\title{
TESTE LERCAFÉ PARA SEMENTES DE CAFEEIRO COM DIFERENTES TEORES DE ÁGUA ${ }^{1}$
}

\author{
JOÃO BATISTA ZONTA; EDUARDO FONTES ARAÚJO; ROBERTO FONTES ARAÚJO"; \\ MÚCIO SILVA REIS 5 ; FLÁVIA MIRANDA GARCIA ZONTA ${ }^{6}$
}

\begin{abstract}
RESUMO - A determinação rápida do potencial germinativo é um fator importante a ser considerado no programa de produção de sementes. Nesse contexto, o teste LERCAFÉ tem se mostrado alternativa promissora, pois é um teste rápido e barato, além de ser de fácil execução e avaliação. Objetivou-se no presente trabalho definir novas combinações de concentração do hipoclorito de sódio, tempo de embebição e temperatura de exposição, para utilização do teste LERCAFÉ em sementes de cafeeiro com diferentes teores de água. Utilizaram-se sementes de café arábica, variedade Catuaí IAC 44, com 33, 23 e 13\% de teor de água (base úmida). As sementes foram avaliadas pelos testes de germinação e LERCAFÉ, sendo este com as seguintes variáveis: embebição em solução de hipoclorito de sódio nas concentrações de 2,5, 3,5 e 4,5\% de cloro ativo, durante período de embebição de uma, duas e três horas, à temperatura de 25,30 e $35^{\circ} \mathrm{C}$. Após terem seu pergaminho removido manualmente, as sementes foram acondicionadas em caixas plásticas para germinação, com tela, onde ficaram embebidas em solução de hipoclorito de sódio, numa concentração, tempo de embebição e temperatura de acordo com as combinações estabelecidas. Para todos os teores de água estudados, as combinações $2,5 \%$ de cloro ativo, a $35^{\circ} \mathrm{C}$, por três horas e $3,5 \%$ de cloro ativo, a $30{ }^{\circ} \mathrm{C}$, por duas horas foram mais eficientes para estimar a germinação de sementes de cafeeiro. Concluiu-se que é possível a utilização do teste LERCAFÉ em sementes com ampla faixa de umidade, bem como reduzir o tempo de embebição das sementes, utilizando temperatura de $30^{\circ} \mathrm{C}$ e concentração de $3,5 \%$ de cloro ativo na solução.
\end{abstract}

Termos para indexação: teste rápido, hipoclorito de sódio, Coffea arabica.

\section{THE LERCAFÉ TEST FOR COFFEE SEEDS WITH DIFFERENT MOISTURE CONTENTS}

\begin{abstract}
Rapid determination of germination potential is important in seed production programs. Coffee (Coffea arabica L.) seeds for planting are marketed with a wide range of water contents because of doubt as to the appropriate values for maintaining seed viability during storage. The nondestructive LERCAFÉ test, based on sodium hypochlorite $(\mathrm{NaOCl})$, correlates well with germination tests and is rapid, cheap and simple to execute and interpret. We assessed different LERCAFÉ test $\mathrm{NaOCl}$ concentrations $(2.5,3.5$ and $4.5 \%$ ative chlorine), seed immersion times (1, 2 and 3 hours) and temperatures $\left(25,30\right.$ and $\left.35^{\circ} \mathrm{C}\right)$ for determining the viability of manually hulled Arabic coffee variety Catuaí IAC 44 seeds with different water contents (33, 23 and 13\%, wet basis). The seeds were also assessed by a standard germination test, which indicated that there was no significant difference in germination frequency between seeds with the different water contents studied. The LERCAFÉ results showed that immersion in $2.5 \%$ active chlorine at $35^{\circ} \mathrm{C}$ for three hours or $3.5 \%$ active chlorine at $30{ }^{\circ} \mathrm{C}$ for two hours were most efficient for estimating germination, indicating that this test can be used over a wide range of water content. To reduce seed immersion times, $30{ }^{\circ} \mathrm{C}$ and $3.5 \%$ active chlorine appear to be the best parameters
\end{abstract}

Index terms: fast test, sodium hypochlorite, Coffea arabica.

${ }^{1}$ Submetido em 19/05/2009. Aceito para publicação em 13/08/2009.

Parte de dissertação de mestrado apresentada a DFT/UFV.

${ }^{2}$ Eng. Agr., Doutorando, Departamento de Fitotecnia, UFV, CEP 36570-000, Viçosa, MG, jobazonta@hotmail.com

${ }^{3}$ Eng. Agr., Dr., Professor Adjunto, Departamento de Fitotecnia, UFV, CEP 36570-000, Viçosa, MG, efaraujo@ufv.br
${ }^{4}$ Eng. Agr., Dr., Pesquisador EPAMIG, CEP 36570-000, Viçosa, MG, rfaraujo@ufv.br

${ }^{5}$ Eng. Agr., Dr., Professor Titular, Departamento de Fitotecnia, UFV, CEP 36570-000, Viçosa, MG, msreis@ufv.br

${ }^{6}$ Eng. Agr., Mestrando, Departamento de Fitotecnia, UFV, CEP 36570-000, Viçosa, MG, flaviaufv@gmail.com 


\section{INTRODUÇÃO}

Em relação à germinação de sementes de cafeeiro, esta ocorre de maneira lenta e desuniforme. Para avaliação da qualidade das sementes, pelo teste de germinação, são necessários 30 dias para a contagem final (Brasil, 1992), o que retarda os trabalhos de pesquisa e comercialização. A germinação das sementes de maneira lenta e desuniforme ainda constitui grande empecilho à produção de mudas de qualidade, causando dificuldades na instalação da cultura no campo (Sguarezi et al., 2001). Outro problema encontrado é a possível ocorrência de situações em que o teste de germinação, por requerer demasiado tempo, possa gerar resultados conflitantes com o verdadeiro potencial fisiológico da semente no momento da divulgação dos resultados (Dias e Silva, 1986). Em relação ao teor de água das sementes, estas são comercializadas com ampla faixa de umidade, devido a informações contrastantes quanto ao valor adequado para a manutenção da viabilidade das sementes durante o armazenamento.

A determinação de forma rápida do potencial germinativo é fator importante a ser considerado no programa de produção de sementes. Atualmente, testes que fornecem resultados em período relativamente curto são os mais demandados, pois com o uso deles é possível agilizar as tomadas de decisão nas diferentes etapas do processo produtivo. Para sementes de cafeeiro, alguns testes vêm sendo utilizados, como os testes de tetrazólio (Delouche e Baskin, 1973), de condutividade elétrica individual (Costa e Carvalho, 2006), de avaliação visual de exsudatos (Sera e Miglioranza, 2000) e de avaliação visual do formato e coloração do embrião (Sera e Miglioranza, 2003); porém, mesmo sendo rápidos, estes testes são muito trabalhosos, onerosos e demandam mão-de-obra especializada.

Nesse contexto, para sementes de cafeeiro, o teste LERCAFÉ tem se mostrado alternativa promissora, pois é um teste rápido e barato, além de ser de fácil execução e avaliação. Desenvolvido por Reis (2004), o teste LERCAFÉ consiste na embebição das sementes de cafeeiro em solução de hipoclorito de sódio. Esta avaliação rápida é possível, uma vez que o hipoclorito de sódio, em determinadas concentrações, reage nas áreas mortas ou lesionadas do endosperma das sementes de cafeeiro, fazendo com que o tecido, nessas condições, assuma coloração esverdeada; se esta coloração ocorrer em grande área do endosperma ou na região sobre e, ou ao redor do embrião, a semente é considerada não germinável. Se a semente apresentar coloração em região distante do embrião ou não apresentar coloração, esta é considerada germinável. A metodologia consiste na embebição de sementes, após terem seu pergaminho removido manualmente, em solução de hipoclorito de sódio, na concentração de $2,5 \%$ de cloro ativo, por três horas, a temperatura de $25^{\circ} \mathrm{C}$, em BOD. Após esse período, as sementes são lavadas em água corrente e avaliadas quanto a sua viabilidade. Este teste tem como vantagens a redução no tempo e no trabalho dispensado na avaliação de sementes de cafeeiro, possibilitando a avaliação rápida da qualidade das sementes, além de apresentar baixo custo e requerer pequena demanda de mão-de-obra. Além de estimar rapidamente a viabilidade das sementes, este teste também pode ser utilizado para verificação da incidência de danos nas sementes, já sendo caracterizados os danos por envelhecimento natural no armazenamento (Zonta et al., 2009) e danos por broca-do-cafeeiro e por secagem a temperaturas elevadas (Zonta et al., 2008).

No desenvolvimento da metodologia do teste LERCAFÉ, Reis (2004) utilizou sementes de cafeeiro com $28 \%$ de teor de água, desconsiderando a ampla faixa de umidade utilizada na comercialização de sementes desta espécie. Ainda, o desenvolvimento de metodologia mais adequada, de modo a definir as condições mais apropriadas de concentração da solução de hipoclorito de sódio, do tempo de embebição e da temperatura, pode tornar o teste ainda mais eficiente.

Baseado nessas considerações o objetivo deste trabalho foi avaliar combinações de concentração de hipoclorito de sódio, tempo de embebição e temperatura de exposição, para esta metodologia, na tentativa de adequar o teste para utilização em sementes com diferentes teores de água e torná-lo ainda mais econômico e rápido.

\section{MATERIAL E MÉTODOS}

O experimento foi conduzido no Laboratório de Pesquisa de Sementes do Departamento de Fitotecnia da Universidade Federal de Viçosa (UFV), em Viçosa, MG. Foram utilizadas sementes de cafeeiro (Coffea arabica L.), cultivar IAC Catuaí 44, provenientes da Fazenda Experimental do Vale do Piranga/Empresa de Pesquisa Agropecuária de Minas Gerais (EPAMIG).

Os frutos foram colhidos manualmente, no estádio denominado cereja. Após a colheita, os frutos foram submetidos aos processos de despolpamento e degomagem (fermentação em água por 24 horas) para a retirada da mucilagem. As sementes foram lavadas em água corrente e dispostas sobre telado à sombra, para remoção do excesso 
de umidade. Em seguida, foram secadas à sombra em sacos de filó, tamanho $10 \times 15 \mathrm{~cm}$, contendo aproximadamente 1,3 $\mathrm{kg}$ de sementes, até atingirem os teores de água de 33, 23 e $13 \%$ (base úmida). Após a secagem, efetuou-se a eliminação de sementes chochas, danificadas e brocadas, conforme os procedimentos para a obtenção de lotes comerciais.

Foram realizados três ensaios, um para cada grau de umidade das sementes. Em cada ensaio, as sementes foram submetidas ao teste LERCAFÉ, com as seguintes variáveis: embebição em solução aquosa contendo hipoclorito de sódio nas concentrações de 2,5, 3,5 e 4,5\% de cloro ativo, durante período de embebição de uma, duas e três horas, à temperatura de 25,30 e $35^{\circ} \mathrm{C}$. A concentração de cloro ativo da solução de pré-embebição foi obtida por meio da diluição do hipoclorito de sódio comercial com água destilada.

Para a realização do teste LERCAFÉ, para todas as combinações estudadas, as sementes, após terem seu pergaminho removido manualmente, foram acondicionadas em caixas plásticas para germinação $(11 \times 11 \times 3,5 \mathrm{~cm})$, onde ficaram embebidas em solução de hipoclorito de sódio, adotando se a proporção de $100 \mathrm{~mL}$ de solução de hipoclorito de sódio para 50 sementes. Para que ficassem imersas, utilizou-se o telado das caixas plásticas sobre as sementes. Após esse procedimento, as caixas foram tampadas e mantidas em câmara de germinação à temperatura de 25,30 e $35^{\circ} \mathrm{C}$, onde permaneceram durante os períodos referentes a cada tratamento (uma, duas e três horas). Decorridos os tempos de exposição das sementes à solução aquosa contendo hipoclorito de sódio, as mesmas foram lavadas em água corrente, durante 90 segundos e imersas em água destilada por 40 minutos, sendo posteriormente dispostas sobre bancada para avaliação. A avaliação visual foi realizada de acordo com a coloração do endosperma e a presença do embrião, determinando-se as porcentagens de sementes germináveis e não germináveis; em seguida, as sementes em análise foram fotografadas. Para obtenção da porcentagem de germinação, foram consideradas germináveis as sementes que não apresentavam coloração verde na região sobre ou próxima ao embrião e com o embrião visível e não germináveis aquelas que apresentavam coloração verde sobre e, ou ao redor do embrião e aquelas que não apresentavam embrião visível; os referidos procedimentos foram realizados seguindo a classificação de Reis (2004).

Para comparação dos resultados, foi realizado o teste de germinação, onde se utilizaram quatro repetições de 50 sementes sem pergaminho, semeadas em papel de germinação, do tipo germitest (três folhas) umedecido com água destilada em quantidade equivalente a 2,5 vezes a massa do papel seco. Os rolos confeccionados foram mantidos em germinador a $30^{\circ} \mathrm{C}$. As avaliações foram efetuadas aos $15 \mathrm{e}$ 30 dias após a semeadura, sendo os resultados expressos em porcentagem de plântulas normais (Brasil, 1992).

Os ensaios foram instalados em delineamento inteiramente casualizado com quatro repetições. Os dados experimentais foram submetidos à análise de variância. Para cada teor de água, os resultados de germinação estimados pelos tratamentos compostos pelas combinações das concentrações de hipoclorito de sódio, temperaturas e tempos de pré-embebição (teste LERCAFÉ), foram comparados com o valor obtido no teste de germinação, aplicando-se o teste de Dunnett unilateral à esquerda, com $5 \%$ de probabilidade e, desta forma, identificando-se os tratamentos que apresentaram resultados inferiores ao tratamento testemunha (teste de germinação).

\section{RESULTADOS E DISCUSSÃO}

A análise de variância mostrou efeito significativo para tempo de embebição e concentração da solução. Apesar do efeito significativo, não se utilizaram as análises para comparação entre médias e nem mesmo a análise polinomial, pois, no presente trabalho, a intenção foi somente comparar, individualmente, os dados da testemunha (teste de germinação), com os resultados do teste LERCAFÉ.

$\mathrm{Na}$ Figura 1, encontram-se as características das sementes classificadas como gemináveis e das sementes classificadas como não germináveis. $\mathrm{Na}$ Tabela 1 encontram-se os valores obtidos para os tratamentos com concentração de $2,5 \%$ de cloro ativo. Para a temperatura de $25{ }^{\circ} \mathrm{C}$ observa-se que os períodos de embebição de uma e duas horas não foram suficientes para promover a coloração esverdeada característica do teste em áreas lesionadas; a igualdade nas médias obtidas em relação à testemunha ocorreu somente pela observação de sementes sem embrião. Para o período de embebição de três horas, as sementes com 23 e $13 \%$ de teor de água apresentaram resultados significativamente iguais às testemunhas. Para a temperatura de $30{ }^{\circ} \mathrm{C}$ foi observada a mesma tendência que à observada para a temperatura de $25^{\circ} \mathrm{C}$, sendo que os períodos de embebição de uma e duas horas não foram suficientes para promover a coloração esverdeada característica do teste em áreas lesionadas e o tempo de embebição de três horas apresentando as sementes com 23 e $13 \%$ de teor de água com valores significativamente iguais às testemunhas. 

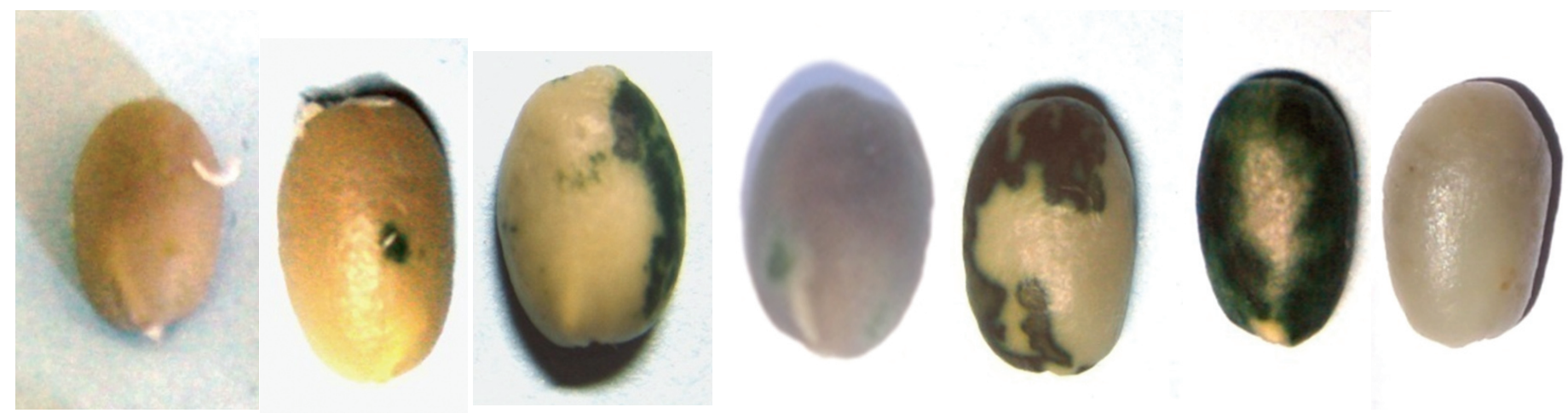

FIGURA 1. Caracterização de sementes de cafeeiro pelo teste LERCAFÉ. A - semente com embrião visível e sem coloração verde; B e C - sementes com embriões visíveis e coloração verde em região distante dos embriões; D, E e F - sementes apresentando coloração verde na região dos embriões; $G$ - semente sem embrião visível.

TABELA 1. Resultados dos testes de germinação (testemunha) e LERCAFÉ, realizados com solução a $2,5 \%$ de cloro ativo, de acordo com a temperatura e o tempo de embebição, em sementes de cafeeiro.

\begin{tabular}{|c|c|c|c|c|c|c|c|c|c|c|}
\hline \multirow{5}{*}{$\begin{array}{l}\text { Teor de água das } \\
\text { sementes }(\%)\end{array}$} & \multirow{5}{*}{$\begin{array}{c}\text { Teste de } \\
\text { germinação }(\%)\end{array}$} & \multicolumn{9}{|c|}{ Teste LERCAFÉ (\% de sementes germináveis) } \\
\hline & & \multicolumn{9}{|c|}{ Temperatura $\left({ }^{\circ} \mathrm{C}\right)$} \\
\hline & & \multicolumn{3}{|c|}{25} & \multicolumn{3}{|c|}{30} & \multicolumn{3}{|c|}{35} \\
\hline & & \multicolumn{9}{|c|}{ Tempo de embebição (horas) } \\
\hline & & $1 * *$ & $2 * *$ & 3 & $1 * *$ & $2 * *$ & 3 & $1 * *$ & $2 * *$ & 3 \\
\hline 33 & 92 & 97 & 98 & 96 & 99 & 98 & 96 & 98 & 97 & $92 *$ \\
\hline 23 & 93 & 97 & 97 & $95^{*}$ & 98 & 98 & $95^{*}$ & 98 & 97 & $93 *$ \\
\hline 13 & 94 & $97 *$ & $97 *$ & $95 *$ & 98 & 98 & $95^{*}$ & 98 & $97 *$ & $92 *$ \\
\hline
\end{tabular}

*Médias iguais ao tratamento testemunha pelo teste de Dunnett a 5\% de probabilidade, na mesma linha. ** Tratamentos não suficientes para coloração das sementes

$\mathrm{Na}$ Tabela 2 encontram-se os valores obtidos para os tratamentos com concentração de $3,5 \%$ de cloro ativo. Analisando-se os resultados, observa-se que, com o aumento da temperatura, ocorre uma diminuição no tempo de embebição necessário para a avaliação. Para a temperatura de $25^{\circ} \mathrm{C}$ observa-se que o período de embebição de uma hora não foi suficiente para promover a coloração esverdeada característica do teste em áreas lesionadas; a igualdade na média obtida em relação à testemunha ocorreu somente pela observação de sementes sem embrião. Os tempos de embebição de duas e três horas apresentaram, para as sementes com 23 e $13 \%$ de teor de água, médias significativamente iguais as das testemunhas. Para a temperatura de $30^{\circ} \mathrm{C}$, o período de embebição de uma hora não foi suficiente para promover a coloração esverdeada característica do teste em áreas lesionadas; a igualdade na média obtida em relação à testemunha ocorreu somente pela observação de sementes sem embrião. O período de embebição de duas horas mostrou-se o mais eficiente para estimar a germinação das sementes de cafeeiro, pois os três teores de água estudados apresentaram médias significativamente iguais às testemunhas. De acordo com a metodologia desenvolvida por Reis (2004) o período de embebição necessário para se obter a coloração característica do teste é de três horas. Assim, esse resultado se mostra de alta relevância, pois a diminuição do período de embebição de três para duas horas faz com que o teste torne-se ainda mais rápido. Para o período de embebição de três horas, 
houve uma subestimação dos valores de germinação encontrados pelo teste. Esses valores subestimados de germinação se devem à alta concentração utilizada, sendo esta responsável pela coloração excessiva das sementes.

TABELA 2. Resultados dos testes de germinação (testemunha) e LERCAFÉ, realizado com solução a 3,5\% de cloro ativo, de acordo com a temperatura e o tempo de embebição, em sementes de cafeeiro.

\begin{tabular}{|c|c|c|c|c|c|c|c|c|c|c|}
\hline \multirow{5}{*}{$\begin{array}{l}\text { Teor de água das } \\
\text { sementes }(\%)\end{array}$} & \multirow{5}{*}{$\begin{array}{c}\text { Teste de } \\
\text { germinação }(\%)\end{array}$} & \multicolumn{9}{|c|}{ Teste LERCAFÉ (\% de sementes germináveis) } \\
\hline & & \multicolumn{9}{|c|}{ Temperatura $\left({ }^{\circ} \mathrm{C}\right)$} \\
\hline & & \multicolumn{3}{|c|}{25} & \multicolumn{3}{|c|}{30} & \multicolumn{3}{|c|}{35} \\
\hline & & \multicolumn{9}{|c|}{ Tempo de embebição (horas) } \\
\hline & & $1 * *$ & 2 & 3 & $1 * *$ & 2 & $3 * * *$ & 1 & $2 * * *$ & $3 * * *$ \\
\hline 33 & 92 & 98 & 95 & 95 & 98 & $94 *$ & 83 & 95 & 54 & 0 \\
\hline 23 & 93 & 98 & $95 *$ & $95 *$ & 97 & $94 *$ & 84 & 96 & 55 & 0 \\
\hline 13 & 94 & $97 *$ & $94 *$ & $94 *$ & $97 *$ & $94 *$ & 82 & $96^{*}$ & 54 & 0 \\
\hline
\end{tabular}

*Médias iguais ao tratamento testemunha pelo teste de Dunnett a 5\% de probabilidade, na mesma linha. ** Tratamentos não suficientes para coloração das sementes. *** Tratamentos que apresentaram coloração excessiva das sementes.

Analisando-se os resultados obtidos na temperatura de $35^{\circ} \mathrm{C}$ (Figura 1), o período de embebição de uma hora não foi suficiente para promover a coloração esverdeada característica do teste em áreas lesionadas; a igualdade na média obtida em relação à testemunha ocorreu somente pela observação de sementes sem embrião. Os períodos de embebição de duas e três horas subestimaram os valores de germinação encontrados pelo teste. Esses valores subestimados de germinação, assim como na temperatura de $30^{\circ} \mathrm{C}$, devem-se à alta concentração utilizada, sendo esta responsável pela coloração excessiva das sementes.

Os valores obtidos para a concentração de $4,5 \%$ de cloro ativo encontram-se na Tabela 3. Para a temperatura de $25{ }^{\circ} \mathrm{C}$, o tempo de embebição de uma hora não foi suficiente para promover a coloração esverdeada característica do teste em áreas lesionadas; a igualdade na média obtida em relação à testemunha ocorreu somente pela observação de sementes sem embrião. Para o período de embebição de duas horas as sementes com 23 e $13 \%$ de teor de água apresentaram resultados significativamente iguais às testemunhas. O período de embebição de três horas subestimou os valores de germinação das sementes. Esses valores subestimados de germinação se devem à alta concentração utilizada, sendo esta responsável pela coloração excessiva das sementes. Para a temperatura de $30{ }^{\circ} \mathrm{C}$ e período de embebição de uma hora, as sementes com 23 e $13 \%$ de teor de água apresentaram resultados significativamente iguais às testemunhas. Para os períodos de embebição de duas e três horas, houve subestimação dos valores de germinação das sementes. Esses valores subestimados de germinação devem-se à alta concentração utilizada, sendo esta responsável pela coloração excessiva das sementes. A temperatura de 35 ${ }^{\circ} \mathrm{C}$ apresentou resultados semelhantes à temperatura de 30 ${ }^{\circ} \mathrm{C}$, sendo que para o período de embebição de uma hora as sementes com 23 e $13 \%$ de teor de água apresentaram resultados significativamente iguais às testemunhas. Para os períodos de embebição de duas e três horas, houve uma subestimação dos valores de germinação das sementes. Esses valores subestimados de germinação se devem à alta concentração utilizada, sendo esta responsável pela coloração excessiva das sementes.

Analisando-se os resultados como um todo, pode-se afirmar que com o aumento da concentração de cloro ativo e da temperatura, há diminuição no período de embebição necessário para se realizar a avaliação. Burch e Delouche (1959), Hsu et al. (1983) e Costa (1992), estudando a metodologia do teste de tetrazólio para sementes de soja, detectaram que temperaturas elevadas podem aumentar a velocidade de embebição da semente, permitindo o entumescimento das mesmas em período relativamente curto, condição fundamental para aceleração do desenvolvimento de coloração das sementes pelo teste e, consequentemente, obtendo-se precioso ganho na redução de tempo para a execução do teste. 
TABELA 3. Resultados dos testes de germinação (testemunha) e LERCAFÉ, realizado com solução a 4,5\% de cloro ativo, de acordo com a temperatura e o tempo de embebição, em sementes de cafeeiro.

\begin{tabular}{|c|c|c|c|c|c|c|c|c|c|c|}
\hline \multirow{5}{*}{$\begin{array}{c}\text { Teor de água das } \\
\text { sementes }(\%)\end{array}$} & \multirow{5}{*}{$\begin{array}{c}\text { Teste de } \\
\text { germinação }(\%)\end{array}$} & \multicolumn{9}{|c|}{ Teste LERCAFÉ (\% de sementes germináveis) } \\
\hline & & \multicolumn{9}{|c|}{ Temperatura $\left({ }^{\circ} \mathrm{C}\right)$} \\
\hline & & \multicolumn{3}{|c|}{25} & \multicolumn{3}{|c|}{30} & \multicolumn{3}{|c|}{35} \\
\hline & & \multicolumn{9}{|c|}{ Tempo de embebição (horas) } \\
\hline & & $1 * *$ & 2 & $3 * * *$ & 1 & $2 * * *$ & $3 * * *$ & 1 & $2 * * *$ & $3 * * *$ \\
\hline 33 & 92 & 98 & 96 & 28 & 96 & 76 & 37 & 95 & 0 & 0 \\
\hline 23 & 93 & 98 & $95^{*}$ & 27 & $95^{*}$ & 76 & 40 & $94 *$ & 0 & 0 \\
\hline 13 & 94 & $97 *$ & $95^{*}$ & 26 & $96 *$ & 74 & 42 & $93 *$ & 0 & 0 \\
\hline
\end{tabular}

*Médias iguais ao tratamento testemunha pelo teste de Dunnett a 5\% de probabilidade, na mesma linha. ** Tratamentos não suficientes para coloração das sementes. $* * *$ Tratamentos que apresentaram coloração excessiva das sementes.

\section{CONCLUSÕES}

Os tratamentos $2,5 \%$ de cloro ativo, a $35^{\circ} \mathrm{C}$, por três horas e $3,5 \%$ de cloro ativo, a $30^{\circ} \mathrm{C}$, por duas horas, são eficientes para estimar a germinação de sementes de cafeeiro com diferentes teores de água.

É possível reduzir o período de embebição das sementes no teste LERCAFÉ, utilizando-se solução a 3,5\% de cloro ativo e temperatura de $30{ }^{\circ} \mathrm{C}$ para todos os teores de água estudados.

É possível a utilização do teste LERCAFÉ em sementes com ampla faixa de umidade.

\section{AGRADECIMENTOS}

Ao CNPq pelo financiamento ao projeto.

\section{REFERÊNCIAS}

BRASIL. Ministério da Agricultura e Reforma Agrária. Regras para análise de sementes. Brasília: SNDA/DNDV/ CLAV, 1992. 365p.

BURCH, J.A.; DELOUCHE, J.C. Absorption of water by seed. Proceedings of the Association of Official Seed Analysis, v.49, p.142-150, 1959.

COSTA, N.P. Metodologia alternativa para o teste de tetrazólio em sementes de soja. 1992. 132f. (Tese Doutorado). Escola Superior de Agricultura "Luiz de Queiroz”, Universidade de São Paulo, Piracicaba, 1992.

COSTA, P.S.C.; CARVALHO, M.L.M. Teste de condutividade elétrica individual na avaliação da qualidade fisiológica de sementes de café (Coffea arabica L.). Ciência e Agrotecnologia, v. 30, n. 1, p. 92-96, 2006.

DELOUCHE, J.C.; BASKIN, N.C. Accelerated aging techniques for predicting the relative storability of seed lots. Seed Science and Technology, v.1, n.2, p. 427-452, 1973.

DIAS, M.C.L.L.; SILVA, W.R. Determinação da viabilidade de sementes de café através do teste de tetrazólio. Pesquisa Agropecuária Brasileira, v.21, n.11, p.1139-1145, 1986.

HSU, J.H.; KIM, C.J.; WILSON, L.A. Factors affecting water uptake of soybean during soaking. Cereal Chemistry, v.60, n.3, p.208-211, 1983.

REIS, L.S. LERCAFÉ: novo teste para estimar a germinação de sementes de cafeeiro (Coffea arabica L.). 2004. 57f. (Dissertação Mestrado). Universidade Federal de Viçosa, Viçosa, 2004.

SERA, G.H.; MIGLIORANZA, E. Avaliação visual do potencial germinativo de sementes de café por exsudatos. In: SIMPÓSIO DE PESQUISA DOS CAFÉS DO BRASIL, 1., 2000, Poços de Caldas. Resumos expandidos... Brasília DF: Embrapa Café Minasplan, 2000.

SERA, G.H.; MIGLIORANZA, E. Avaliação visual do potencial germinativo de sementes de café pelo formato e coloração do embrião. Semina, v.24, n.2, p.307-310, 2003.

SGUAREZI, C.N.; BRACCINI, A.L.; SCAPIM, C.A.; BRACCINI, M.C.L.; DALPASQUALE, V.A. Avaliação de tratamentos pré-germinativos para melhorar o desempenho de sementes de café (Coffea arabica L.). II. Processo de umidificação. Revista Brasileira de Sementes, v.23, n.2, p. 162-170, 2001.

ZONTA, J.B.; ARAÚJO, E.F.; ARAÚJO, R.F.; REIS, M.S. 
Uso do teste Lercafé para a caracterização de danos em sementes de cafeeiro. Pesquisa Agropecuária Brasileira, v.43, n.11, p.1601-1607, 2008.
ZONTA, J.B.; ARAÚJO, E.F.; ARAÚJO, R.F.; REIS, M.S.; LIMA, J.S.. LERCAFÉ test for the assessment of coffee seed quality during storage. Seed Science and Technology, v.37, n.1, p.140-146, 2009. 